\title{
INFLUÊNCIA DA TEMPERATURA NA FLUÊNCIA DE PILARES PAREDE DE CONCRETO
}

\author{
INICIAL DO NOME. SOBRENOME: E. MADUREIRA \\ Profissão: Professor \\ Instituição: Universidade Federal do Rio Grande do Norte - UFRN \\ Estado; País: Rio Grande do Norte; Brasil \\ e-mail: edmadurei@ct.ufrn.br
}

\section{RESUMO}

Um membro de concreto armado, solicitado permanentemente mediante a ação de carga, apresenta deformações progressivas com o tempo, associadas à fluência do material. As formulações pioneiras envolvendo o fenômeno em destaque são aplicáveis, sobretudo, se a intensidade das tensões se mantiver constante. Sua adoção na análise de membros de concreto armado, que experimentam variações na intensidade de tensões durante o transcurso do referido fenômeno, requer simplificações das quais resultam os modelos de memória, cuja desvantagem é a necessidade de armazenamento de todo o histórico de tensões. Os modelos de estado originam-se de modificações apropriadas do esquema de integração de modo a dispensar tal volume de armazenamento. O objertivo deste trabalho é a análise do efeito da temperatura sobre o desempenho mecânico de pilares parede tendo em vista a fluência do concreto, realizada a partir do emprego de modelo de estado. Os resultados obtidos realçam o efeito acelerador da temperatura sobre o processo deformacional em evidência, antecipando o patamar de tensões que solicitam as barras da armadura de aço.

Palavras-chave: concreto, fluência, temperatura,influência

\begin{abstract}
A concrete member, kept under sustained loads, presents progressive deformations over time, associated to creep. The pioneering formulations of the phenomenon are applicable when the magnitude of the stresses remains constant. Its application to reinforced concrete members, which exhibits change in the stress magnitude over the highlighted phenomenon development, requires simplifications from which result the memory models, which have the disadvantage of requiring the storage of the stress history. The state models are improved from the integrating scheme changing and provide such storage amount. The aim of this work is the temperature effects analysis in the mechanical performance of thin-walled columns considering the creep of concrete, carried out on the base of a state model. The obtained results show that the temperature accelerates the deformational process associated to creep anticipating the asymptotic level of the stresses in the reinforcement steel bars.
\end{abstract}

Keywords: concrete, creep, temperature, influence

\section{INTRODUÇÃO}

As tensões que solicitam, permanentemente, a massa de um corpo sólido de concreto promovem deformações progressivas, adicionais àqueles referentes à resposta imediata ao carregamento, caracterizando o fenômeno conhecido por Fluência.

Tais deformações estão associadas, sobretudo, ao comportamento mecânico da camada de água de natureza, essencialmente, viscosa frente às tensões de serviço, que permanece adsorvida à superfície das partículas de cimento no concreto endurecido, mesmo a elevadas temperaturas.

Seus efeitos são mais acentuados, nos primeiros anos da vida útil da estrutura, quando as deformações associadas apresentam taxas mais elevadas, podendo delongar-se até cinco anos, evoluindo em suas fases mais avançadas, entretanto, mediante taxas mais moderadas.

As deformações por Fluência podem assumir magnitude de até três vezes a deformação imediata ao carregamento resultando deslocamentos estruturais em escala similar. 
Dentre os fatores que interferem no material influenciando a deformação lenta tem-se a umidade ambiental, a temperatura, a consistência do concreto fresco e a resistência do concreto endurecido. A proporção dos agregados graúdos, a taxa de armadura, e as dimensões do elemento estrutural, por sua vez, afetam a deformação global do sólido.

As deformações por Fluência modificam os campos de tensões e, portanto, a configuração de equilíbrio em membros estruturais de concreto armado, de modo que, sua abstração, constitui fonte de dissonância entre o projeto e a realidade.

Em pilares parede, tais deformações promovem a redução das tensões na massa de concreto e sua elevação nas barras da armadura de aço, podendo induzir estas últimas ao escoamento.

As formulações pioneiras voltadas para a modelagem da deformação lenta baseiam-se no conceito do Coeficiente de Fluência. São aplicáveis a elementos para os quais as tensões solicitantes mantêm-se constantes. Dos artifícios voltados para a sua adequação a elementos que apresentam variações de tensões no decorrer do fenômeno resultam os Modelos de Memória que exigem o armazenamento do histórico de tensões, e, portanto, volume de armazenamento excessivo, a ponto de inviabilizar a sua utilização.

Com o propósito voltado à racionalização operacional do espaço de memória de armazenamento, foram desenvolvidos, a partir do refinamento do esquema de integração, os Modelos de Estado, que preveem em sua formulação o manuseio computacional da intensidade das tensões referentes, exclusivamente, ao instante de tempo anterior ao considerado.

O objetivo deste trabalho é a análise do desempenho mecânico de pilares parede com base em aproximação por elementos finitos, em estado plano de tensões, considerando as deformações por Fluência do concreto, conforme modelo de estado e valores para os parâmetros pertinentes ao fenômeno em destaque fixados a partir das recomendações da NBR 6118 (ABNT, 2014), atentando-se, sobretudo, para o efeito da temperatura.

\section{MODELAGEM}

Em problemas bi-dimensionais envolvendo análise estrutural, a matriz constitutiva referente ao modelo ortotrópico nãolinear é definida tomando-se por base, as deformações equivalentes, dadas por:

Os índices “i”" e " $\mathbf{j}$ ” representam as direções principais, os " $\mathbf{D}_{\mathbf{i j}}$ " os elementos da matriz constitutiva, e os parâmetros $\boldsymbol{\varepsilon}_{\mathbf{i}}$ e $\boldsymbol{\varepsilon}_{\mathbf{j}}$ são as deformações segundo as direções principais. Para o concreto em compressão foram adotadas as relações de HOGNESTAD (1951), expressas na forma:

onde " $\sigma_{\mathbf{p}}$ " é a tensão de pico do concreto, " $\varepsilon_{\mathbf{p}}$ " sua deformação correspondente, e, " $\boldsymbol{\varepsilon}_{\mathbf{c u}}$ " a deformação limite de ruptura do material. Para o concreto em tração, adotou-se um modelo de fissuras distribuídas, cujas vantagens são considerar a continuidade do campo de deslocamentos, e, dispensar modificações de natureza topológica da malha de elementos finitos, no decorrer da análise.

Adotou-se para o concreto o módulo de deformação reduzido, NBR 6118 (ABNT, 2014), dado por:

As tensões limite no concreto foram obtidas da envoltória de KUPFER e GERSTLE (1973), apresentada na forma:

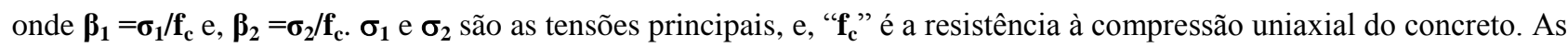
deformações de pico em compressão biaxial da massa de concreto foram obtidas conforme as expressões: 
onde $\boldsymbol{\beta}_{1}=\sigma_{1 \mathrm{p}} / \mathbf{f}_{\mathrm{c}}, \boldsymbol{\beta}_{2}=\boldsymbol{\sigma}_{2 \mathrm{p}} / \mathbf{f}_{\mathrm{c}}$ e " $\boldsymbol{\varepsilon}_{\mathrm{co}}$ " é a deformação correspondente à tensão de compressão de pico do concreto para estado uniaxial de tensões.

Para a modelagem do concreto submetido a estado plano de tensões, é utilizada a relação constitutiva incremental de DESAI e SIRIWARDANE (1972).

$\mathrm{Na}$ análise em pauta foram adotados elementos finitos isoparamétricos de aproximação quadrática. A região da massa de concreto foi discretizada a partir de elementos planos quadriláteros $\mathbf{Q 8}$ e as barras da armadura de aço mediante elementos lineares $\mathbf{L 3}$.

As deformações por Fluência foram simuladas a partir do modelo de estado proposto por KAWANO e WARNER (1996), sendo dadas mediante:

onde

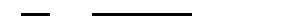

e

são as parcelas de endurecimento e de efeito visco-elástico, respectivamente. As funções $\Phi_{\mathrm{d}}(\mathrm{t}, \tau)$ e $\Phi_{\mathrm{v}}(\mathrm{t}, \tau)$ representam os coeficientes de Fluência correspondentes. Para o presente trabalho foram utilizadas as versões incrementais apresentadas conforme as equações:

com:

Sendo $\phi_{d}^{*}$ e $\phi_{v}^{*}$ os coeficientes finais de Fluência. $\boldsymbol{T}_{\boldsymbol{v}}$ é o tempo de retardamento. Em cada instante $\mathbf{t}_{\mathbf{n}}$ as deformações por Fluência serão dadas por:

Com:

O efeito da temperatura foi modelado a partir do procedimento recomendado pela NBR 6118 (NBR, 2014), segundo o qual a idade do concreto em cada data de observação deve ser ajustada resultando a idade fictícia calculada mediante:

Onde $\boldsymbol{\alpha}$ é um coeficiente dependente da velocidade de endurecimento do cimento; $\mathbf{T}_{\mathrm{i}}$ é a temperatura média diária do ambiente em graus Celsius; $\Delta \mathbf{t}_{\mathbf{e f}, \mathbf{i}}$ é o período durante o qual a temperatura média diária do ambiente $\mathbf{T}_{\mathbf{i}}$ pode ser admitida constante.

Para os fins deste trabalho admitiu-se que a intensidade das tensões que solicitam a massa de concreto mantém-se constantes durante cada intervalo de tempo e sua variação a nível global, ao longo de todo o período de observação do fenômeno, é expressa mediante função do tipo degrau. 
Para os efeitos do bojo deste trabalho o comportamento do aço da armadura do concreto armado, por sua vez, foi considerado elástico perfeitamente plástico.

\section{SUPORTE COMPUTACIONAL}

Os resultados destw trabalho foram obtidos mediante a utilização d "software" Análise Constitutiva Não Linear ACNL, baseado no método dos elementos finitos e escrito em linguagem FORTRAN. O referido código computacional inclui em sua pauta algorítmica a formulação dos elementos isoparamétricos de aproximação quadrática, lineares $\mathbf{L 3}$, figura 1.a, voltados para a simulação das barras de aço, e planos quadriláteros Q8, figura 1.b, destinados à discretização da região da massa de concreto. As imagens referentes aos campos de deslocamentos foram geradas a partir do aplicativo NLPOS, PITANGUEIRA e PARENTE JR (1997), enquanto aquelas correspondentes aos campos de tensões foram produzidas a partir do aplicativo PROJECT1, elaborado em DELPH 10.2, MADUREIRA e SILVA (2013).

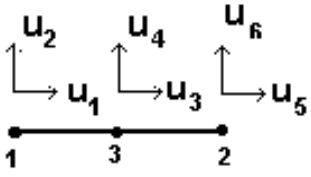

(a)

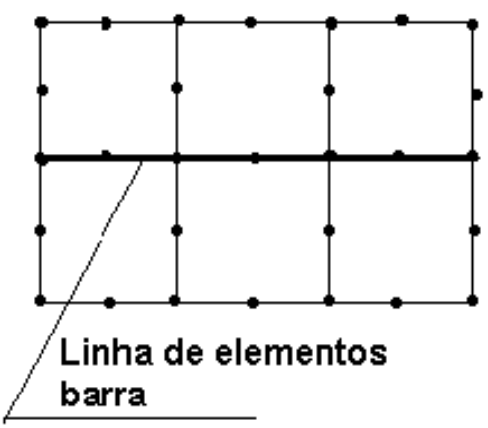

(b)

Figura 1: Elementos finitos: a - ) Lineares L3; b - ) Planos Q8

\section{VALIDAÇÃO DO PROGRAMA}

Os resultados obtidos a partir do programa foram comparados com os seus correspondentes obtidos através de algoritmo simplificado baseado nos postulados da Mecânica dos Sólidos, modalidade unidimensional, MADUREIRA et al (2011), constatando-se boa concordância, Figura 2 .

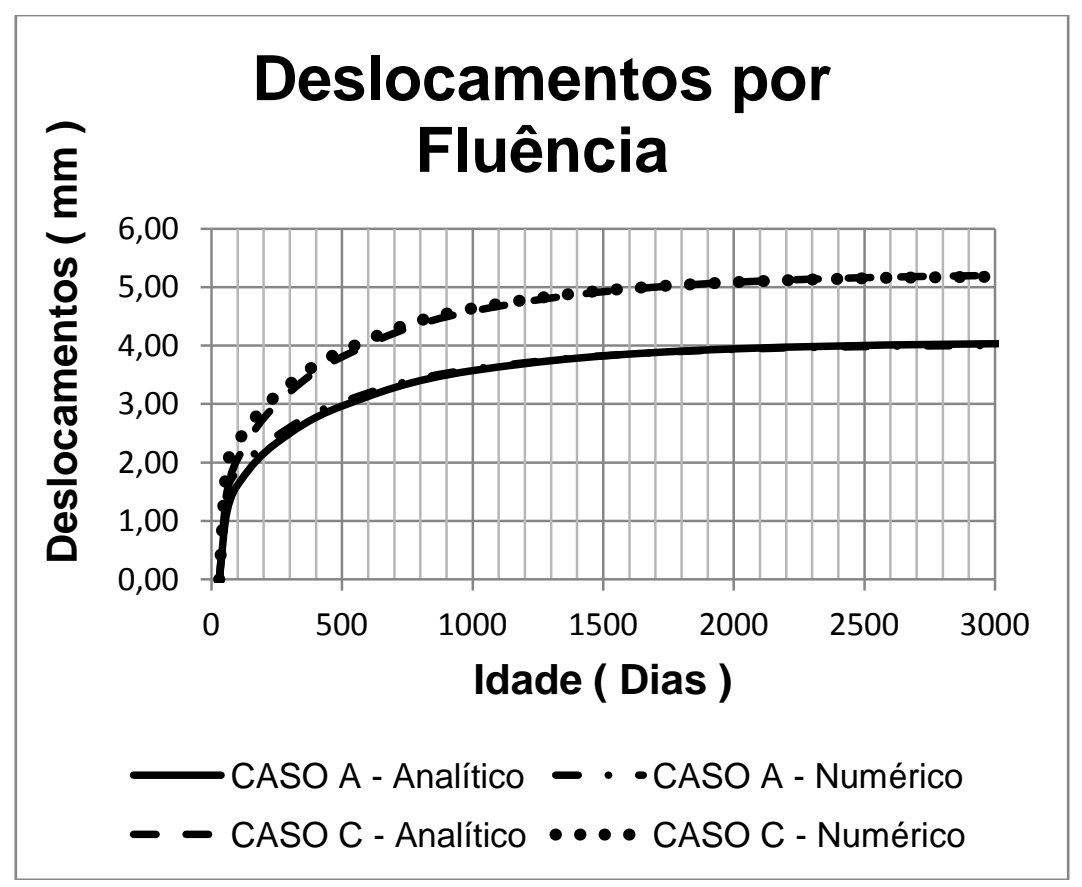

Figura 2: Curvas dos deslocamentos por fluência com o tempo 


\section{MODELOS ANALISADOS}

Os modelos objeto de análise são pilares-parede com altura de 3,00 m e seção transversal retangular definida a partir da fixação de sua largura em 1,20 m e de sua espessura em 0,20 m, Figura 3.

O domínio do problema foi definido no plano "xy" conforme apresentado na Figura 3, consoante a simetria do modelo estrutural, discretizado adotando-se para ambos os tipos de elementos dimensão de 0,10 m, originando malha de elementos finitos com 180 elementos planos e 90 elementos unidimensionais

Os referidos membros estruturais são manufaturados em concreto de cimento Portland de endurecimento lento, de consistência na condição fresca referente ao abatimento de slump test compreendido na faixa de $\mathbf{5} \mathbf{c m}$ a $\mathbf{9} \mathbf{c m}$, de classe de resistência à compressão $\mathbf{C 3 0}$, armado mediante barras longitudinais de aço CA-50 distribuídas conforme Figura 3.

Os referidos pilares são solicitados mediante carga distribuída uniformemente na seção de seu topo, Figura 3, aplicada aos 30 dias contados a partir da data da concretagem, com intensidade fixada em $3750 \mathrm{kN}$, correspondente a tensões de compressão na massa de concreto com magnitude de $50 \%$ de sua resistência, atendendo assim às limitações próprias do modelo de deformações por Fluência da NBR 6118 (NBR, 2014).

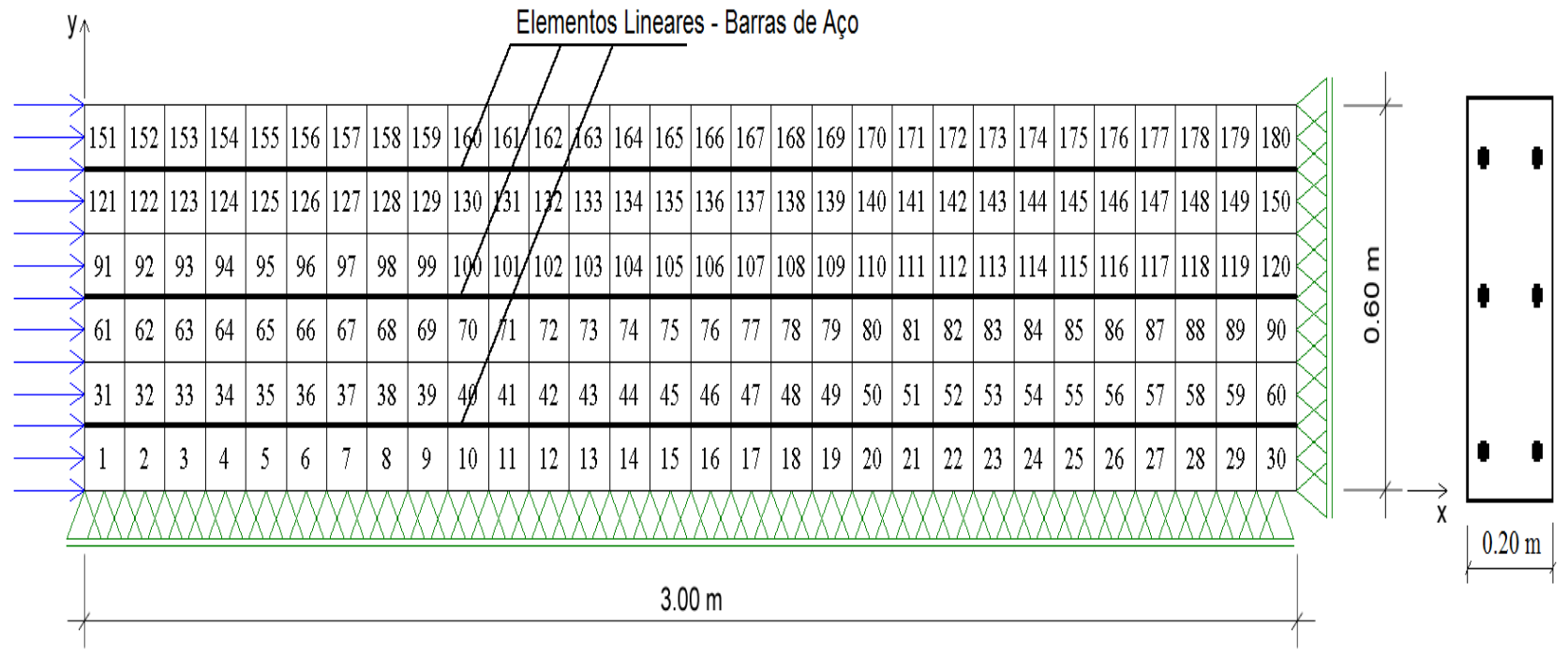

Figura 3: Malha de elementos finitos e domínio do problema pilar parede

A análise em pauta foi realizada em estado plano de tensões considerando-se dez casos diferenciados entre si pelo teor de umidade e pela temperatura, Tabela 1.

O tempo de retardamento foi fixado em 600 dias. Para o coeficiente final de fluência de endurecimento foi fixado o valor de $\mathbf{0}$. Os valores do coeficiente final de fluência associados aos efeitos viscoelásticos, , constam na Tabela 1.

Tabela 1 - Modelos Analisados

\begin{tabular}{|c|c|c|c|}
\hline Casos & Temperatura $\left({ }^{\circ} \mathbf{C}\right)$ & Umidade $(\%)$ & \\
\hline 1 & 20 & 40 & 1,63 \\
\hline 2 & 40 & 40 & 1,63 \\
\hline 3 & 60 & 40 & 1,63 \\
\hline 4 & 80 & 40 & 1,63 \\
\hline 5 & 100 & 40 & 1,63 \\
\hline 6 & 20 & 60 & 0,92 \\
\hline 7 & 40 & 60 & 0,92 \\
\hline 8 & 60 & 60 & 0,92 \\
\hline 9 & 80 & 60 & 0,92 \\
\hline 10 & 100 & 60 & 0,92 \\
\hline
\end{tabular}


As curvas do coeficiente de fluência com o tempo, referentes aos resultados obtidos mediante o modelo recomendado pela NBR 6118 (NBR, 2014) e o modelo de estado empregado neste trabalho, apresentam boa concordância, Figura 4, corroborando-se, portanto, que os valores dos parâmetros do modelo de estado foram apropriadamente fixados.

Uma vez examinando-se as curvas da Figura 4, constata-se que, aos 2000 dias de idade do concreto, o processo deformacional associado à Fluência do material, já havia sido estabilizado, de modo que tal idade foi considerada como limite extremo do prazo de estudo do fenômeno em destaque, adotando-se, para fins de análise, os instantes de observação nas idades do concreto aos 33, 40, 55, 90, 180, 380, 860 e 2000 dias.

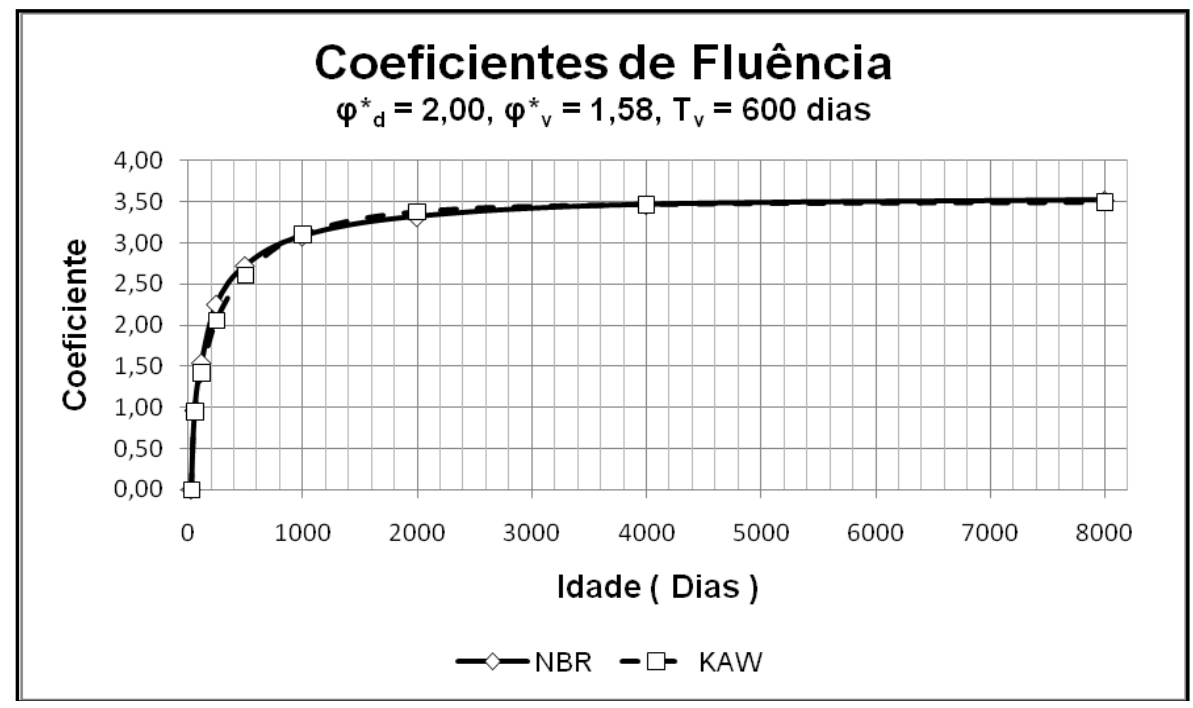

Figura 4: Coeficiente de fluência com o tempo.

\section{RESULTADOS}

Para todos os casos estudados, uma vez atingida a configuração de equilíbrio referente à carga solicitante, o campo de deslocamentos e o de tensões normais na direção " $\mathrm{x}$ " assumiram as distribuições indicadas nas Figuras 5 e 6 , respectivamente. A magnitude do deslocamento no topo do pilar parede foi da ordem de 2,0 mm, enquanto a tensão de compressão na massa de concreto apresentou intensidade próxima dos $15 \mathrm{MPa}$. A intensidade da tensão nas armaduras de aço, por sua vez, estacionou em torno de $144 \mathrm{MPa}$.
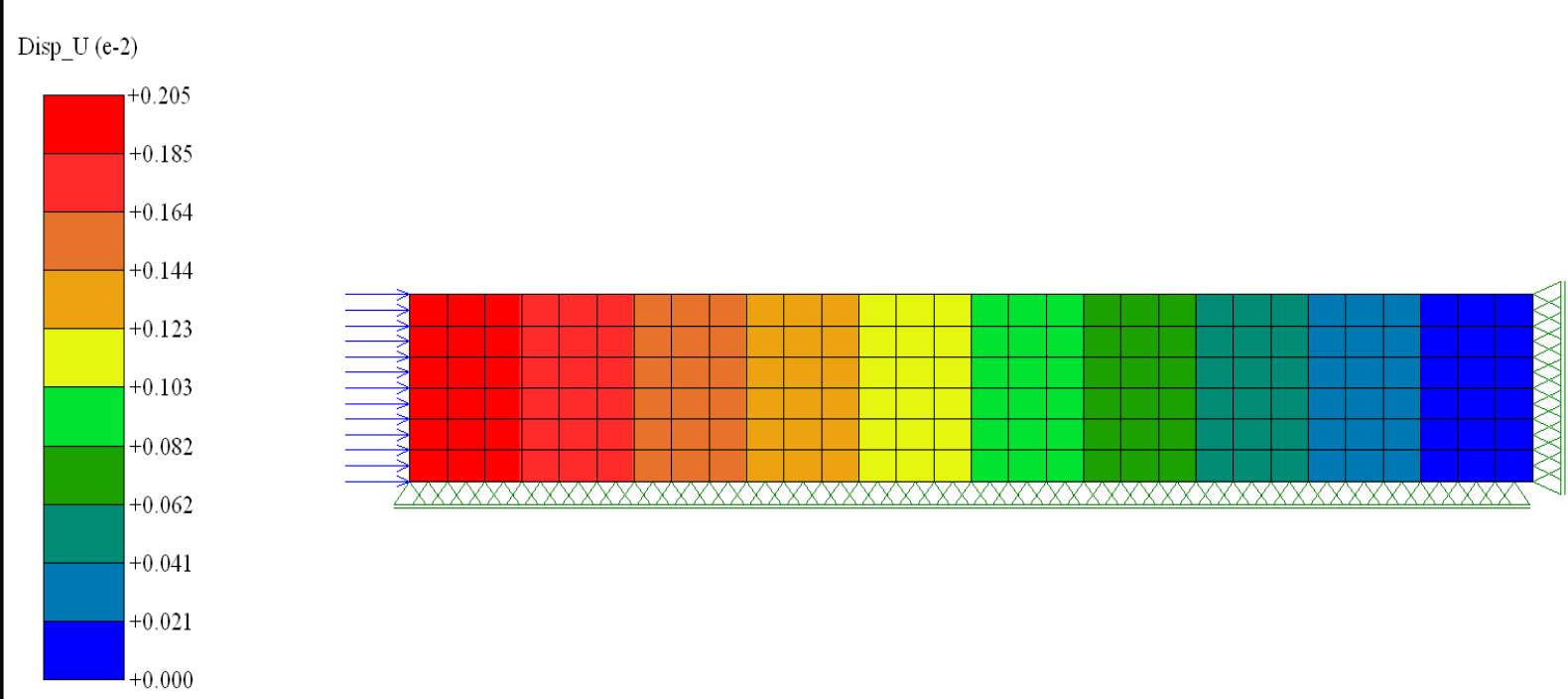

Figura 5: Campo de deslocamentos longitudinais imediatos ao carregamento - Caso 1 
O campo de tensões normais na massa de concreto na direção "x", Figura 6, apresenta distribuição praticamente uniforme, ressaltando-se, porém, a ocorrência de tênue perturbação na zona de introdução de carga, localizada na vizinhança do topo do pilar.

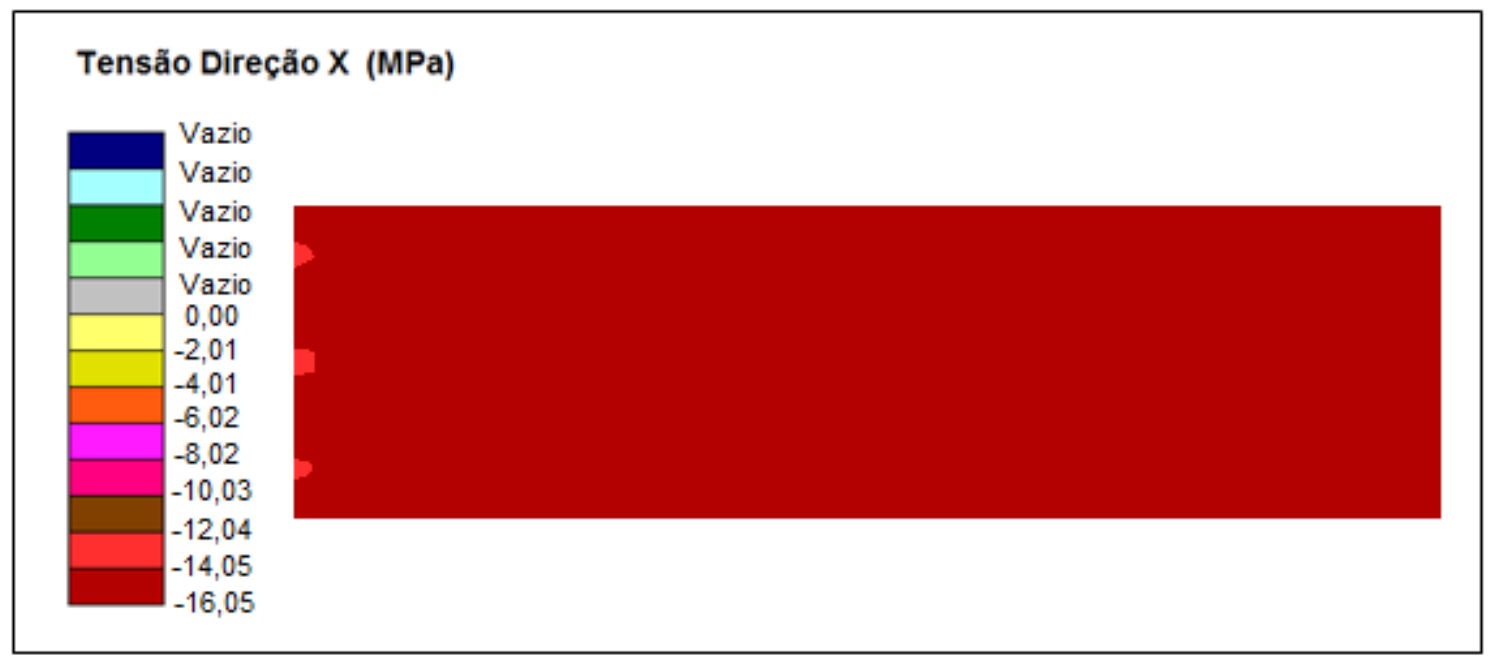

Figura 6: Campo de tensões normais no instante imediato ao carregamento - Caso 1 pilar parede.

Uma vez tendo se manifestado o fenômeno de Fluência do concreto foram deflagrados deslocamentos adicionais do topo dos pilares que evoluíram com o tempo conforme tendência caracterizada pelas curvas da Figura 7. Observe-se que ao final do prazo de 2000 dias, contados a partir da data de produção do concreto, tais deslocamentos já haviam praticamente sido estabilizados, quando os campos correlatos assumiram distribuições na forma indicada na Figura 8.

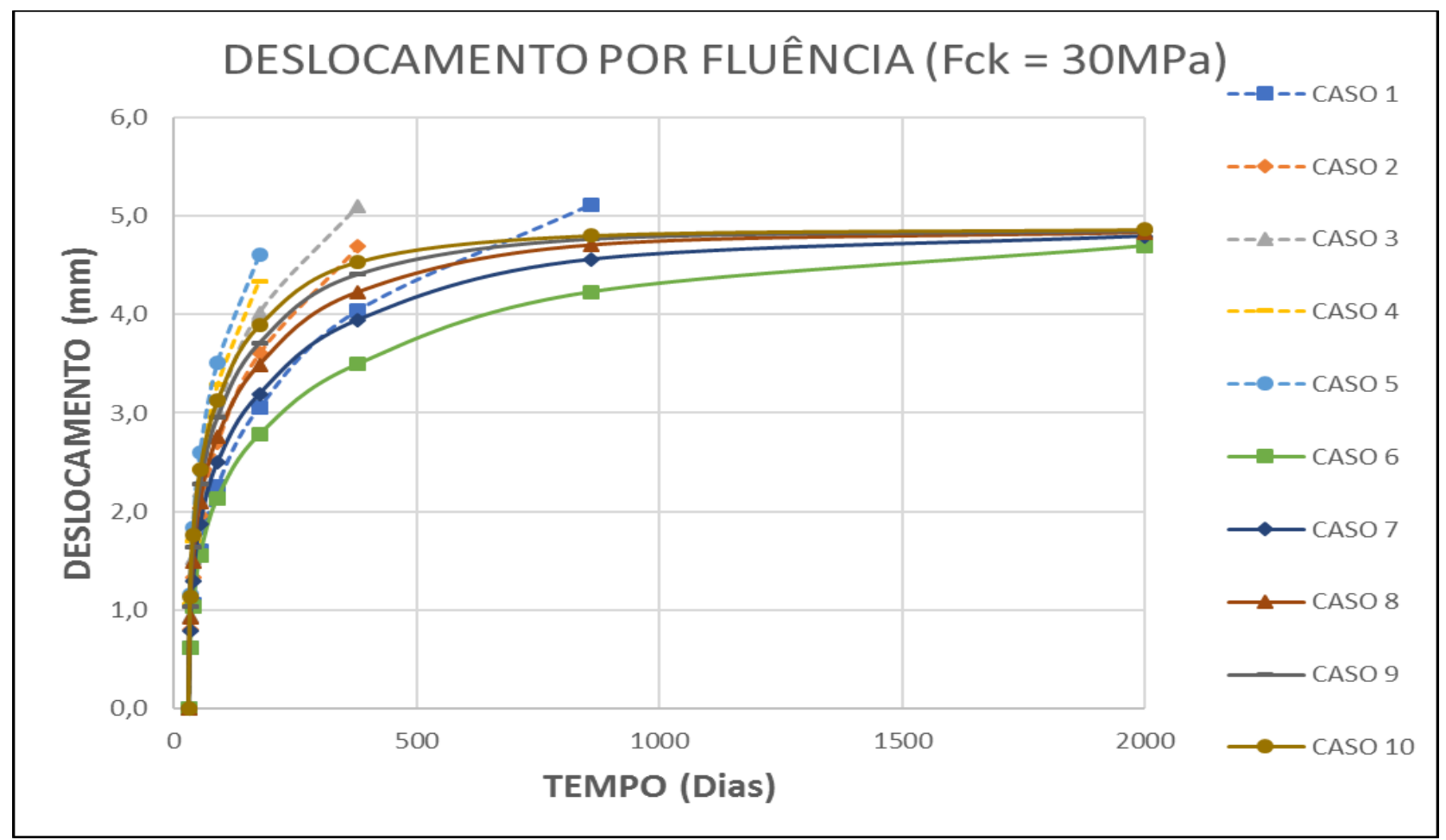

Figura 7: Curvas de deslocamento por fluência como tempo

Para fins de estabelecimento de base comparativa coerente da variação dos parâmetros pertinentes, neste trabalho a idade de 180 dias foi tomada como referência, pois, conforme será observado adiante neste relato, considerando-se todos os casos estudados, tal idade corresponde ao menor período, contado a partir da usinagem do concreto, ao fim do qual ocorreu o fenômeno de escoamento do aço das armaduras do concreto armado. 


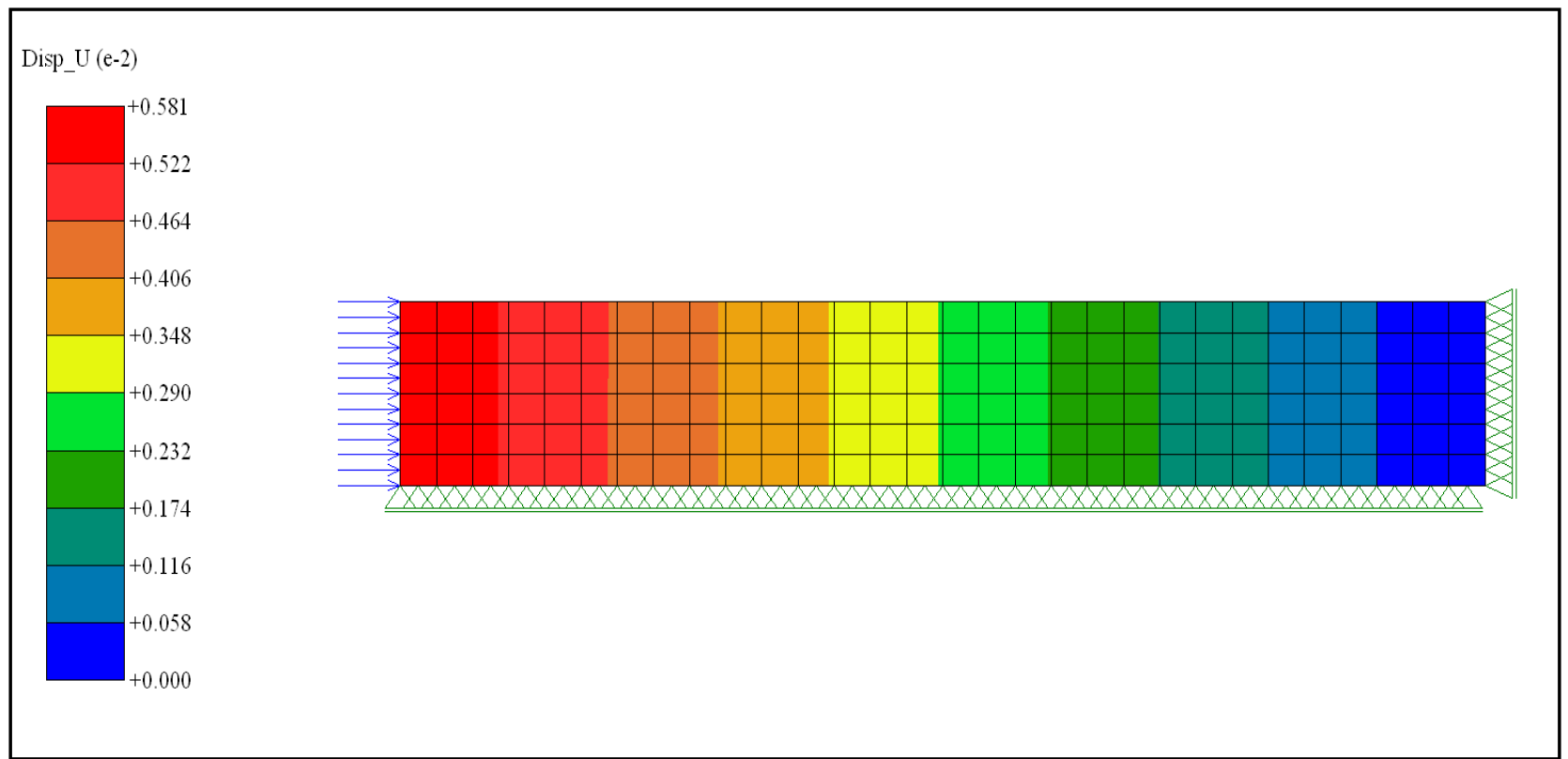

Figura 8: Campo de deslocamentos longitudinais devido à fluência aos 2000 dias - Caso 1

Conforme os resultados obtidos, o menor acréscimo de deslocamento por Fluência, aos 180 Dias de idade do concreto, foi de 2,8 mm, correspondendo a 1,4 vezes o deslocamento no instante imediato ao carregamento, e foi assinalado para o caso 6, Tabela 2, que se refere ao maior teor de umidade e à menor temperatura. O maior deslocamento por Fluência, desencadeado no decorrer do referido período, foi da ordem de 4,6 mm, representando 2,3 vezes o deslocamento imediato ao carregamento, Tabela 2, registrado para o caso 5, concernente ao menor teor de umidade e a maior temperatura. Em exame mais pormenorizado do grupo de curvas referentes aos casos 1, 2, 3, 4 e 5, referentes ao teor de umidade de $40 \%$, diferindo caso a caso, unicamente, pela temperatura, constata-se que os deslocamentos por Fluência apresentam valores maiores para temperaturas maiores. Adotando-se conduta idêntica sobre o grupo de curvas referentes aos casos 6, 7, 8, 9 e 10, aos quais corresponde teor de umidade de $60 \%$, observa-se comportamento similar, entretanto, o deslocamento final, decorrido até a estabilização do fenômeno, apresenta, praticamente, a mesma magnitude.

A partir da análise dos resultados obtidos constata-se que as deformações por Fluência provocaram alívio de tensões na massa de concreto, que evoluíram consoante as curvas da Figura 9.

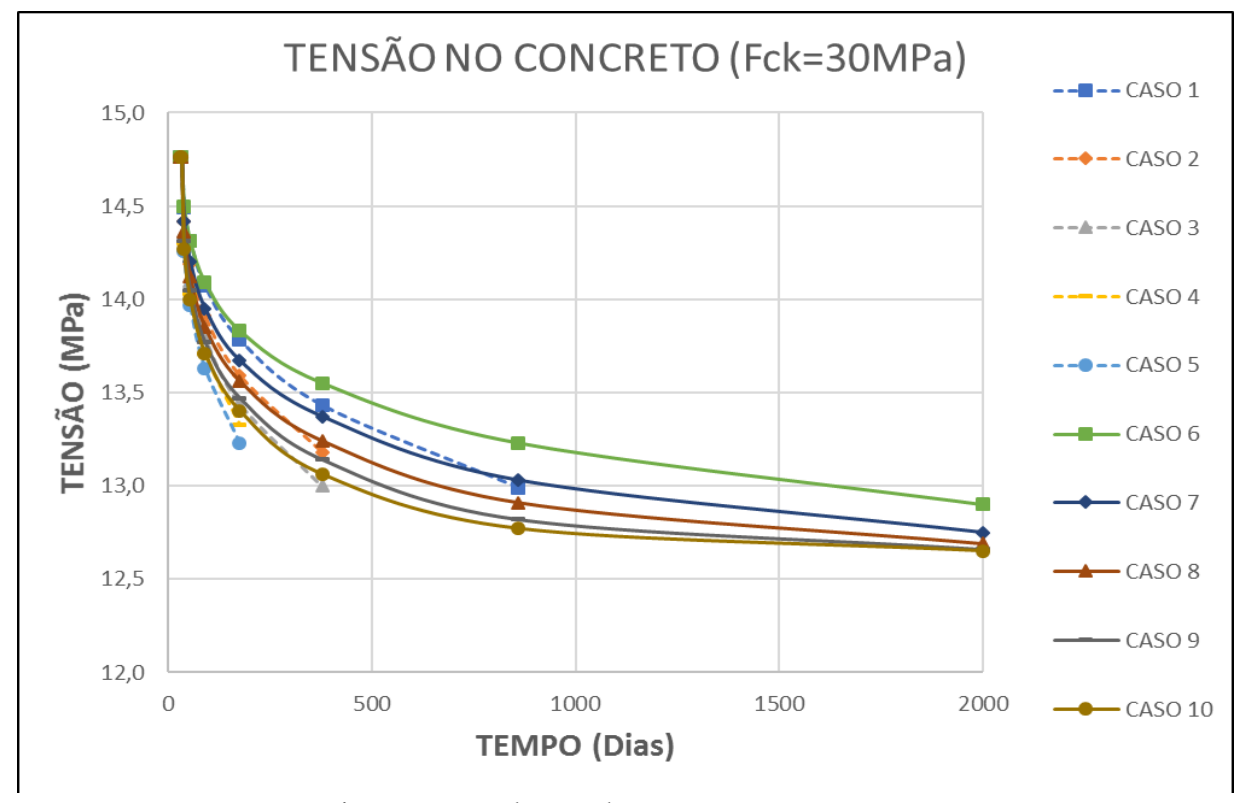

Figura 9: Evolução das tensões no concreto 
Para o caso 1, as tensões na massa de concreto estabilizaram-se aos 2000 dias conforme as distribuições indicadas no campo da Figura 9, a partir da qual pode-se observar que a perturbação de tensões já reportadas neste texto, intensificou-se devido às deformações por fluência. O campo de tensões da figura 9 , também constitui referência para a descrição comportamental dos demais casos, ressaltando-se, porém que, em alguns casos o processo foi interrompido precocemente, pelo escoamento do aço da armadura relatado adiante. O menor alívio de tensões foi de 6,8\%, registrado para os casos 1 e 6, referentes à menor temperatura, enquanto, o maior foi de $8,2 \%$, registrado para o caso 5 , referente ao menor teor de umidade e à maior temperatura.

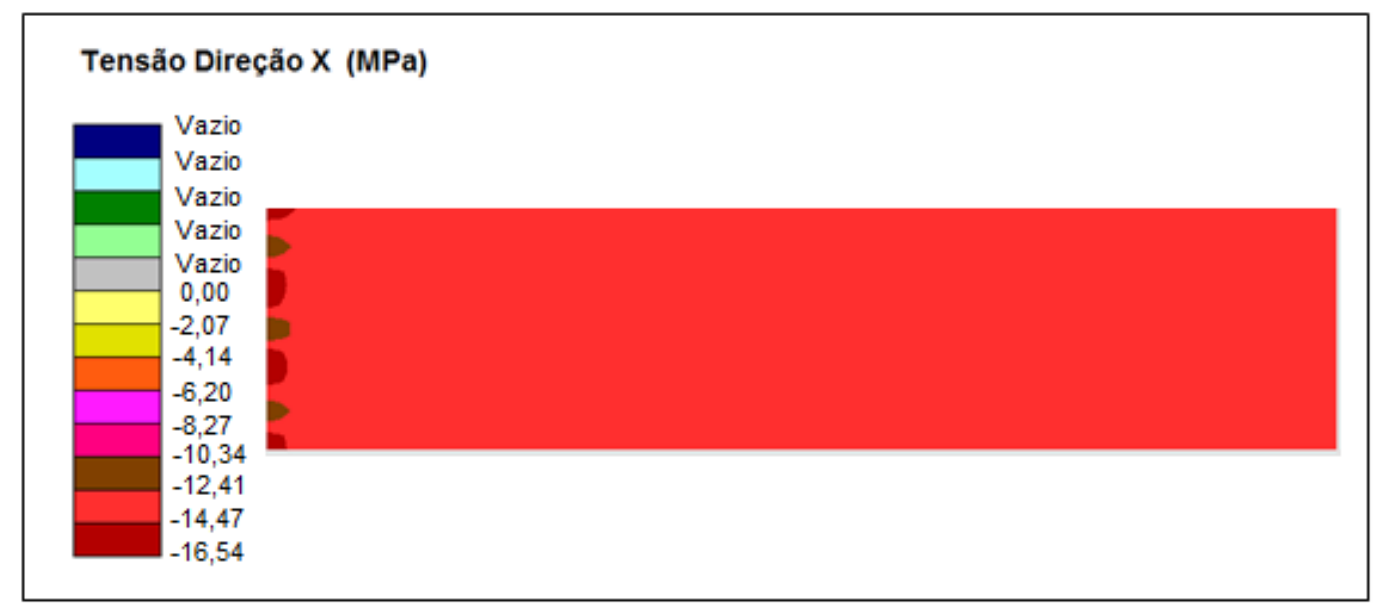

Figura 10: Campo de tensões normais aos 2000 dias - Caso 1

Em decorrência das Deformações por Fluência as tensões nas barras da armadura de aço evoluíram conforme as curvas da Figura 10, constatando-se aumento em suas intensidades. A partir da Tabela 2 constata-se que o menor acréscimo de tensões nas barras de aço foi de $135 \%$, registrado para o caso 6, referente ao maior teor de umidade e à menor temperatura. O maior foi de $223 \%$, registrado para o caso 5, de menor teor de umidade e maior temperatura, e culminou no escoamento do aço da armadura aos 180 dias de idade do concreto. Para os casos de 1 a 5 a tensão no aço atingiu o limite de escoamento, que ocorreu tanto mais precocemente quanto maior a temperatura.

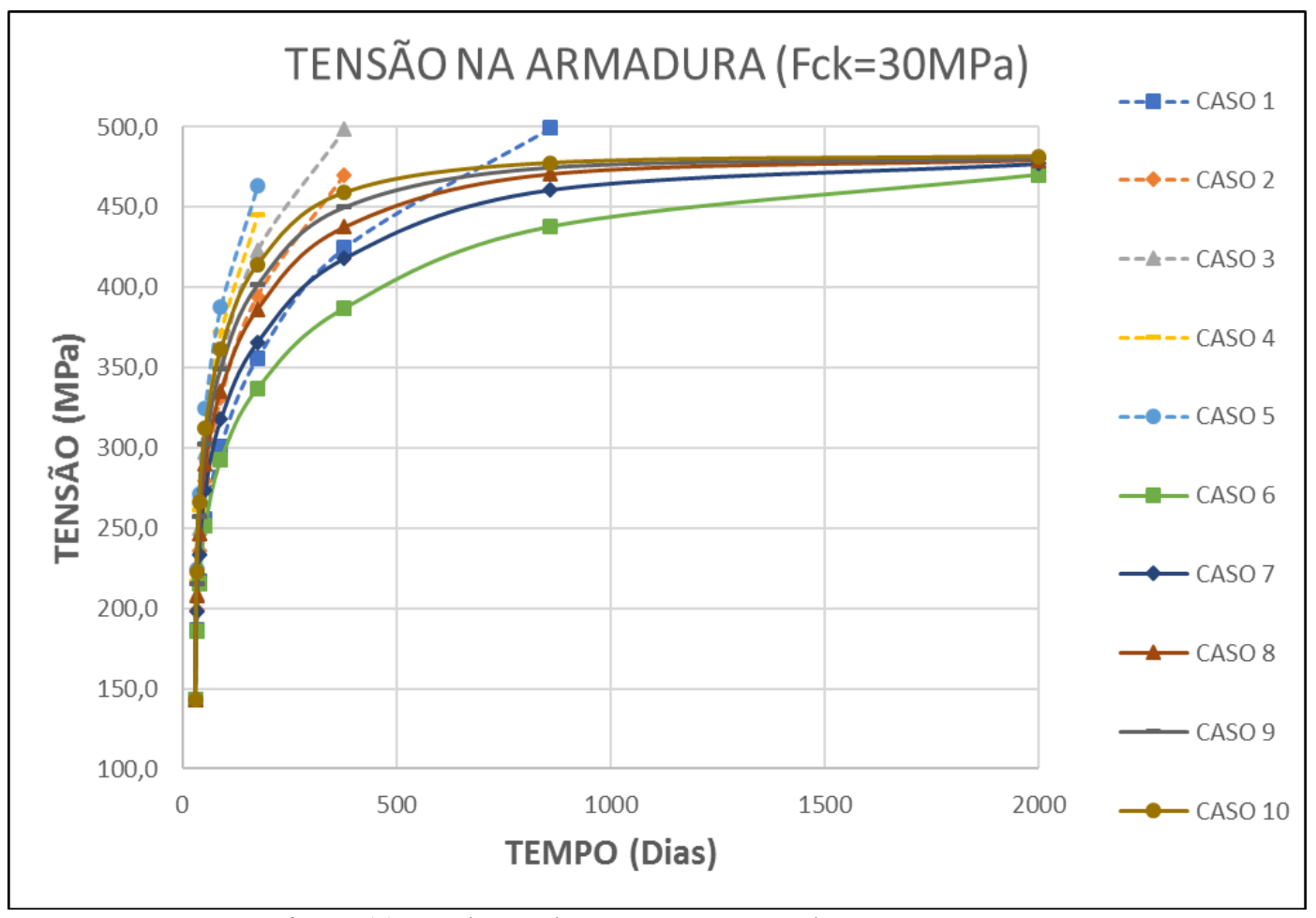

Figura 11: Evolução das tensões na armadura com o tempo 
Tabela 2 - Deslocamentos e Tensões por Fluência do Concreto

\begin{tabular}{|c|c|c|c|c|c|c|c|}
\hline \multirow{3}{*}{ Casos } & \multirow{2}{*}{\multicolumn{2}{|c|}{ Deslocamentos (mm) }} & \multicolumn{4}{|c|}{ Tensões (MPa) } & \multirow[b]{2}{*}{ Idade Final (Dias) } \\
\hline & & & \multicolumn{2}{|c|}{ Massa de Concreto } & \multicolumn{2}{|c|}{ Armadura de Aço } & \\
\hline & 180 Dias & Final & 180 Dias & Final & 180 Dias & Final & \\
\hline 1 & 3,1 & 5,11 & 13,7 & 13,0 & 355 & 499 & 860 \\
\hline 2 & 3,6 & 4,69 & 13,5 & 13,2 & 394 & 470 & 380 \\
\hline 3 & 4,0 & 5,10 & 13,3 & 13,0 & 423 & 498 & 380 \\
\hline 4 & 4,4 & 4,34 & 13,2 & 13,3 & 445 & 445 & 180 \\
\hline 5 & 4,6 & 4,60 & 13,1 & 13,2 & 463 & 463 & 180 \\
\hline 6 & 2,8 & 4,70 & 13,7 & 12,9 & 338 & 470 & 2000 \\
\hline 7 & 3,2 & 4,80 & 13,6 & 12,8 & 366 & 477 & 2000 \\
\hline 8 & 3,5 & 4,83 & 13,5 & 12,7 & 386 & 479 & 2000 \\
\hline 9 & 3,7 & 4,85 & 13,4 & 12,7 & 401 & 481 & 2000 \\
\hline 10 & 3,9 & 4,86 & 13,3 & 12,7 & 414 & 482 & 2000 \\
\hline
\end{tabular}

\section{CONCLUSÕES}

Este trabalho se refere à análise do desempenho mecânico de pilares parede a partir de uma formulação ortotrópica não linear e aproximação por elementos finitos, considerando as deformações por Fluência do concreto com base em modelo de estado, destacando-se a avaliação do efeito da temperatura no fenômeno em estudo.

Com vistas ao cumprimento de tal objetivo foram estudados dez casos diferenciados entre si pela Temperatura e pelo Teor de Umidade.

A partir dos resultados obtidos constatou-se que, considerando-se todos os casos analisados, as deformações por Fluência praticamente já haviam se estabilizado ao final de 2000 dias de idade do concreto com deslocamentos correspondentes de até 2,3 vezes o deslocamento verificado no instante imediato ao carregamento.

Observou-se, inclusive, o alívio de tensões de compressão na massa de concreto, em decorrência do fenômeno em destaque, já reportado por MADUREIRA et al (2013), PAIVA (2015) e FONTES (2017), com redução percentual de até $8,2 \%$, verificada para o caso 5 referente ao menor teor de umidade e à maior temperatura.

Os resultados obtidos revelaram que as deformações por Fluência promoveram acréscimo de tensões nas barras da armadura culminando, para os casos de 1 a 5 , correspondentes ao menor teor de umidade, no escoamento do aço, que como era de se esperar ocorreu tanto mais precocemente quanto maior a temperatura, pois, tais tensões desenvolvem-se consonantemente as deformações por Fluência, que seguiram tal tendência.

Os resultados obtidos corroboraram as previsões da NBR 6118/2014, no tocante à influência da temperatura nas deformações por Fluência, pois, indicaram que, em temperaturas maiores os deslocamentos no decorrer do desenvolvimento do fenômeno são maiores e sua estabilização é mais precoce, mas, sua magnitude ao ser atingindo o regime estacionário mostrou-se independe do nível térmico vigente.

\section{REFERÊNCIAS}

ASSOCIAÇÃO BRASILEIRA DE NORMAS TECNICAS. NBR 6118: Projeto de Estruturas de Concreto Armado - Procedimento, Rio de Janeiro, 2014.

DESAI, C.S. e SIRIWARDANE, H.J. Constitutive Laws for Engineering Material. Prentice-Hall, New Jersey, 1972.

FONTES, B. V. C. Efeitos da Temperatura nas Deformações por Fluência do Concreto. Monografia de Trabalho de Conclusão de Curso. Natal, Rio Grande do Norte: DEC/CT/UFRN, 2017.

HOGNESTAD, E.. A Study of Combined Bending and Axial Load in Reinforced Concrete Members. University of Illinois Bulletin, 1951. 
KAWANO, A., E WARNER, R. F.. Model Formulations for Numerical Creep Calculations for Concrete. Journal of structural Engineering, Vol. 122, № 3, March. ASCE, pp. 284-290, 1996.

KUPFER, H.B. e GERSTLE, K.H. Behaviour of Concrete under Biaxial Stresses. Journal of Engineering Mechanics, Vol. 99, n. 4, pp. 853-866, 1973.

MADUREIRA, E.L., SIQUEIRA, T. M. e da SILVA, J.C.. Deformações por Fluência em Pilares de Concreto Armado. 53 Congresso Brasileiro do Concreto. Florianópolis - Santa Catarina - Brasil, 2011.

MADUREIRA, E.L, SIQUEIRA, T. M. e RODRIGUES, E.C. Análise de Vigas Incluindo a Fluência do Concreto. 55 Congresso Brasileiro do Concreto. Gramado - Rio Grande do Sul - Brasil, 2013.

MADUREIRA, E.L. e SILVA, A.L.A. PROJECT1 - Programa para visualização de campos de tensões resultantes de analises não lineares de modelos bidimensionais de elementos finitos. Versão 1.0, Rio Grande do Norte: DEC/UFRN, 2013.

PAIVA, L. A., Análise de parâmetros influentes nas deformações por fluência em pilares parede de concreto armado. Trabalho de Conclusão de Curso. Natal, Rio Grande do Norte: DEC/CT/UFRN, 2015.

PITANGUEIRA, R. L. S. e PARENTE JR., E. NLPOS - Programa para visualização de resultados de analises não lineares de modelos bidimensionais de elementos finitos. Versão 1.0, Rio de Janeiro: DEC/PUC-Rio, 1997. 